\title{
GIÁ TRI TIÊN LƯợNG CỦA CHỈ SỐ VIÊM-MIỄN DICH HỆ THỐNG TRONG UNG THƯ PHỔI KHÔNG TẾ BÀO NHỎ GIAI ĐOẬN III, IV
}

\section{TÓM TẮT}

Mục tiêu: Đánh giá giá trị tiên lượng của chỉ số viêm-miễn dịch hể thống (systemic immuneinflammation-SII) trước điêu trị với sống thêm của bênh nhân ung thư phổi không tế bào nhỏ giai đoạn tiến triển, di căn điều trị hóa chất bước một. Đối tượng và phương pháp: Nghiên cứu mô tả cắt ngang có theo dõi dọc trên 51 bệnh nhân ung thư phế quản phổi không tế bào nhỏ giai đoạn III,IV điều trị hóa chất bước một tại Trung tâm Ung bướu Bệnh viện Trung ương Thái Nguyên từ 01/01/2017 đển $31 / 12 / 2018$. Chỉ số viêm miễn dịch hệ thốngSII trước điều trị được tính bằng số lượng tiểu câu x tỷ lệ bạch cầu đa nhân trung tính/bach cầu lympho. Điểm cut-off của chỉ số SII được xác định bằng đường cong ROC. Thời gian sống thêm trung bình được tính bằng phương pháp ước lượng thời gian theo sự kiện của Kaplan- Meier. Sử dụng phương pháp kiểm định Logrank test và mô hình hồi qui Cox nhằm khảo sát các yếu tố tiên lướng ảnh hưởng đến tỷ lệ sống thêm toàn bộ. Kết quả: 22 bệnh nhân có chỉ số SII cao $(\geq 1.409)$ và 29 bênh nhân có chỉ số SII thấp (<1.409). Thời gian sống thêm trung bình là 23,7 tháng ở nhóm SII thấp và 13,1 tháng ở nhóm có SII cao $(p<0,05)$. Phân tích đa biến cho thấy chỉ số SII trước điều trịvà chỉ số PS là yếu tố tiên lượng độc lập cho sống thêm toàn bộ. Kết luận: Chỉ số SII trước điều trị là yếu tố tiên lượng độc lập cho ung thư phổi không tế bào nhỏ giai đoạn tiến triển, di căn hóa trị bước môt.

Tư khhóa: chỉ số viêm miễn dịch hệ thông, ung thư phổi không tế bào nhỏ, hóa trị, yếu tố tiên lượng.

\section{SUMMARY \\ THE PROGNOSTIC ROLE OF SYSTEMIC IMMUNE-INFLAMMATION IN III-IV STAGE NON-SMALL CELL LUNG CANCER PATIENTS \\ Objective: To assess the prognostic role of pre- tretment systemic immune-inflammation index (SII) in advaced, metastsis non-small cell lung cancer patients treated with first-line chemotherapy. Methods: cross- sectional study design was conducted on 51 III-IV stage non-small cell lung cancer patients treated with first-line chemotherapy at Oncology Center of Thai Nguyen National Hospital from 01/01/2017 to $31 / 12 / 2018$. SII index was calculated using formula: platlet count $x$ neutrophil/lymphcyte count. The oftimal cut-off value was calculated by ROC curve. The median overall survival time (OS) were estimated}

*Trường Đại học Y dước Thái Nguyên

Chịu trách nhiệm chính: Trần Thị Kim Phượng

Email: phuonghong433tn@gmail.com

Ngày nhận bài: 22.10.2020

Ngày phản biện khoa họ: 27.11.2020

Ngày duyệt bài: 9.12.2020

\section{Trần Thị Kim Phượng*, Lê Phong Thu*}

using Kaplan-Meier method. A Log-rank test and Coxregression model were carried out for univariate and multivariate analyses. Results: 22 patients had high SII $(\geq 1.409)$ and 29 patients had low SII $(<1.409)$. The median OS time was 23,7 months in low SII group and 13,1 months in high SII group $(p<0,05)$. At multivariate analysis, pre-treatment SII and ECOG-PS were independent prognostic factors for worst OS. Conclusions: Pre-treament SII is independent prognostic factor for advaced non-small cell lung cancer patients treated with frst-line chemotherapy.

Key words: systemic immune-inflammation, nonmall cell lung cancer, chemotherapy, prognostic factor.

\section{I. ĐẶT VẤN ĐỀ}

Ung thư phổi được chia thành hai nhóm là ung thư phổi không tế bào nhỏ (UTPKTBN) và ung thư phổi tế bào nhỏ, trong đó, UTPKTBN chiếm khoảng $85-90 \%$ tổng số ca ung thư phổi [4]. Phần lớn các trường hợp UTPKTBN được chẩn đoán ở giai đoạn tiến triển, di căn và có tiên lượng xấu. Phương pháp điêu trị chủ yếu là hóa trị hoặc điều trị đích. Tuy nhiên, kết quả điều trị thường khiêm tốn và bên cạnh đó, phần lớn các ca bệnh kém nhạy cảm với các tác nhân hóa trị $[1],[3],[6],[7]$. Kháng hóa chất và tái phát hoặc di căn xa là một trong những yếu tố ảnh hưởng lớn đến kết quả điều trị. Chính vì vậy, việc tìm ra yếu tố có giá trị hướng dẫn lựa chọn quyết định điều trị cũng như tiên đoán khả đáp ứng điều trị và tiên lượng về sống thêm là một yêu cầu cấp thiết.

Một trong các yếu tố được đánh giá và được xác định có liên quan đến tiên lượng của bệnh ung thư là yếu tố viêm. Yếu tố này đóng vai trò quan trọng trong bệnh sinh cũng như thúc đẩy sự tiến triển của các các bệnh ung thư nói chung. Các dấu ấn của viêm như tăng số lượng bạch cầu đa nhân trung tính và tiểu cầu, hay tỷ lệ bạch cầu đa nhân trung tính/lympho bào, chỉ số dinh dưỡng... liên quan đến tiên lượng xâu của các bệnh lý ung thư nói chung trong đó có ung thư phổi không tế bào nhỏ đã được một số nghiên cứu đề cập đến. Gần đây, chỉ số viêmmiễn dịch hệ thống SII được tính bằng số lượng tiểu cầu $x$ số lượng bạch cầu đa nhân trung tính/số lượng lymphobào đã được một số nghiên cứu trên thế giới chứng minh có giá trị tiên lượng độc lập trong một số bệnh ung thư trong đó có ung thư phổi không tế bào nhỏ $[1],[3],[6],[7]$. Tuy nhiên, chỉ số này chưa được nghiên cứu 
nhiều ở Viêt Nam và hiên tai, chưa có nghiên cứu nào tương tự được tiến hành tại Trung tâm Ung bướu Bệnh viện Trung ương Thái Nguyên. Vì vậy, chúng tôi thực hiện đề tài này nhằm đánh giá giá trị tiên lượng của chỉ số viêm-miễn dịch hệ thống với sống thêm trên bệnh nhân ung thư phổi không tế bào nhỏ giai đoạn III,IV điều trị hóa chất bước một tại Trung tâm Ung bướu Bệnh viện Trung ương Thái Nguyên.

\section{II. ĐỐI TƯợNG VÀ PHƯƠNG PHÁP NGHIÊN CỨU}

- 51 bệnh nhân ung thư phổi không tế bào nhỏ giai đoạn III,IV điều trị hóa chất bước một tại Trung tâm Ung bướu Bệnh viện TW Thái Nguyên từ 01/01/2017 đến 31/12/2018.

- Tiêu chuẩn chọn bệnh nhân: tuổi $\geq 18 ; P S \leq$ 2; được chẩn đoán xác định bằng mô bệnh học tại u hoặc hạch;chẩn đoán xác định UTPKTBN bằng mô bệnh học, chẩn đoán giai đoạn III, IV theo phân loại của UICC/AJCC 2010; bệnh nhân được chẩn đoán và điều trị hóa chất lần đầ; có hồ sơ lưu trữ đầy đủ; có thông tin về tình trạng bệnh sau điều trị qua các lần tái khám định kỳ và/hoặc qua trả lời thư theo mẫu. Loại trừ các bệnh nhân giai đoạn III được điều trị bằng xạ trị; bệnh nhân có tằng bạch cầu, tiểu cầu do các bệnh lý khác; bỏ dở điều trị;đđiều trị ban đầu tại cơ sở khác.

- Thiết kế nghiên cứu: mô tả cắt ngang có theo dõi doc.

- Thời gian nghiên cứu: 01/01/202031/10/2020. Địa điểm: Trung tâm Ung bướu Bệnh viện Trung ương Thái Nguyên.

- Hồi cứu hồ sơ bệnh án, ghi nhận các thông tin theo mẫu bệnh án nghiên cứu, theo dõi sống thêm của bệnh nhân qua thư và điện thoại. Chì tiêu nghiên cứu chính bao gồm chỉ số viêm miễn dịch hệ thống SII trước điều trị được tính bằng số lượng tiểu cầu $x$ tỷ lệ bạch cầu đa nhân trung tính/bạch cầu lympho, thời gian sống thêm, tỷ lệ sống thêm. Thời điểm cuối lấy thông tin về sống thêm của bệnh nhân là 31/10/2020.

- Xử lý số liệu bằng phần mềm tin học SPSS 16.0. Điểm cut-off của chỉ số SII được xác định bằng đường cong ROC. Thời gian sống thêm trung bình được tính bằng phương pháp ước lượng thời gian theo sự kiện của Kaplan- Meier. Sử dụng phương pháp kiểm định Log- rank test và mổ hình hồi qui Cox nhằm khảo sát các yếu tố tiên lượng ảnh hưởng đến tỷ lệ sống thêm toàn bộ. Lựa chọn khoảng tin cậy $95 \%(p<0,05)$.

- Bài báo là một phần của đề tài nghiên cứu khoa học, tuân thủ yêu câu về đạo đức trong nghiên cứu, đã được Hội đồng đạo đức Trường Đại học Y Dược Thái Nguyên thông qua.

\section{KẾT QUẢ NGHIÊN CỨU}

\section{1. Đặc điểm chung của đối tượng} nghiên cứu

Bảng 1. Đặc điểm chung của nhóm bệnh nhân nghiên cứu

\begin{tabular}{|c|c|c|c|}
\hline \multicolumn{2}{|c|}{ Đăc điếm } & n (51) & $\%$ \\
\hline \multirow{2}{*}{ Giới } & Nam & 35 & 68,6 \\
\hline & Nữ & 16 & 31,4 \\
\hline \multirow{2}{*}{ Tuổi } & Trung bình & $57,6(31-72)$ & \\
\hline & Trung vị & 59 & \\
\hline \multirow{2}{*}{$\begin{array}{l}\text { Nhóm } \\
\text { tuổi }\end{array}$} & $<60$ & 26 & 51,0 \\
\hline & $\geq 60$ & 25 & 49,0 \\
\hline \multirow{2}{*}{$\begin{array}{c}\text { Chỉ số } \\
\text { PS }\end{array}$} & $0-1$ & 29 & 56,9 \\
\hline & 2 & 22 & 43,1 \\
\hline \multirow{2}{*}{$\begin{array}{c}\text { Giai } \\
\text { đoạn T }\end{array}$} & $\mathrm{T} 1,2$ & 16 & 31,4 \\
\hline & $\mathrm{T} 3,4$ & 35 & 68,6 \\
\hline \multirow{4}{*}{$\begin{array}{c}\text { Giai } \\
\text { đoạn N }\end{array}$} & NO & 10 & 19,6 \\
\hline & N1 & 2 & 3,9 \\
\hline & $\mathrm{N} 2$ & 10 & 19,6 \\
\hline & N3 & 29 & 56,9 \\
\hline \multirow{2}{*}{$\begin{array}{l}\text { Giai } \\
\text { đoạn }\end{array}$} & III & 20 & 39,2 \\
\hline & IV & 31 & 60,8 \\
\hline \multirow{3}{*}{$\begin{array}{c}\text { Mô } \\
\text { bệnh } \\
\text { học }\end{array}$} & $\begin{array}{l}\text { Ung thư biếu } \\
\text { mô tuyến }\end{array}$ & 43 & 84,3 \\
\hline & $\begin{array}{l}\text { Ung thư biếu } \\
\text { mô vảy }\end{array}$ & 8 & 15,7 \\
\hline & Loại khác & 0 & 0 \\
\hline \multirow{2}{*}{$\begin{array}{c}\text { CEA } \\
(n=29)\end{array}$} & Thấp & $8 / 29$ & 27,6 \\
\hline & Cao & $21 / 29$ & 72,4 \\
\hline \multirow{4}{*}{$\begin{array}{l}\text { Phác đồ } \\
\text { điêu trị }\end{array}$} & $\begin{array}{l}\text { Taxane + } \\
\text { Platinum }\end{array}$ & 34 & 66,7 \\
\hline & $\begin{array}{l}\text { Gemcitabin+ } \\
\text { Platinum }\end{array}$ & 3 & 5,9 \\
\hline & $\begin{array}{c}\text { Vinorelbin + } \\
\text { Platinum }\end{array}$ & 7 & 13,7 \\
\hline & $\begin{array}{l}\text { Pemetrexed } \\
+ \text { Platinum }\end{array}$ & 7 & 13,7 \\
\hline
\end{tabular}

\subsection{Các yếu tố tiên lượng}

Roc Curve

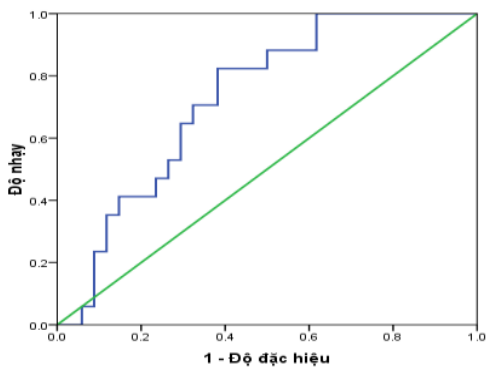

Biểu đồ 1. Xác định điểm cut-off của chỉ số SII trước điều trị 
Diện tích dưới đường cong ROC 0,777 kết quả sống thêm toàn bộ của bệnh nhân. Điểm $(77,7 \%), p=0,01$. Chỉ số SII có giá trị phân biệt cut-off tối ưu của chỉ số SII là 1.409.

Bảng 2. Các đặc điểm của nhóm nghiên cứu theo mức độ SII

\begin{tabular}{|c|c|c|c|c|c|}
\hline \multirow{2}{*}{\multicolumn{2}{|c|}{ Đặc điểm }} & \multirow{2}{*}{$\begin{array}{l}n=51 \\
(100 \%)\end{array}$} & \multicolumn{2}{|c|}{ SII } & \multirow[t]{2}{*}{ p } \\
\hline & & & Thấp $(<1.409)$ & Cao $(\geq 1.409)$ & \\
\hline \multirow{2}{*}{ Giới } & Nam & $35(68,6)$ & $21(72,4)$ & $14(63,6)$ & \multirow[b]{2}{*}{0,503} \\
\hline & Nữ & $16(31,4)$ & $8(27,6)$ & $8(43,1)$ & \\
\hline \multirow{2}{*}{ Tuổi } & $<60$ & $26(51,0)$ & $12(41,4)$ & $14(63,6)$ & \multirow[b]{2}{*}{0,115} \\
\hline & $\geq 60$ & $25(49,0)$ & $17(58,6)$ & $8(36,4)$ & \\
\hline \multirow{2}{*}{ Chỉ số PS } & $0-1$ & $29(56,9)$ & $18(62,1)$ & $11(50,0)$ & \multirow[b]{2}{*}{0,389} \\
\hline & 2 & $22(43,1)$ & $11(37,9)$ & $11(50,0)$ & \\
\hline \multirow{2}{*}{$\begin{array}{c}\text { Giai đoạn } \\
\text { u }\end{array}$} & $T 1,2$ & $16(31,4)$ & $9(31,0)$ & $7(31,8)$ & \multirow[b]{2}{*}{0,952} \\
\hline & $T 3,4$ & $35(68,6)$ & $20(69,0)$ & $15(68,2)$ & \\
\hline \multirow{2}{*}{$\begin{array}{l}\text { Giai đoạn } \\
\text { hạch }\end{array}$} & $N(-)$ & $10(19,6)$ & $7(24,1)$ & $3(13,6)$ & \multirow[b]{2}{*}{0,483} \\
\hline & $\mathrm{N}(+)$ & $41(89,4)$ & $22(75,9)$ & $19(86,4)$ & \\
\hline \multirow{2}{*}{ Giai đoạn } & III & $20(39,2)$ & $16(55,2)$ & $4(18,2)$ & \multirow{2}{*}{0,007} \\
\hline & IV & $31(60,8)$ & $13(44,8)$ & $18(81,8)$ & \\
\hline \multirow{2}{*}{$\begin{array}{l}\text { Mô bệnh } \\
\text { học }\end{array}$} & $\begin{array}{c}\text { Ung thư biếu mô } \\
\text { tuyến }\end{array}$ & $43(84,3)$ & $25(86,2)$ & $18(81,8)$ & \multirow[b]{2}{*}{0,713} \\
\hline & $\begin{array}{l}\text { Ung thư không phải } \\
\text { biểu mô tuyênn }\end{array}$ & $8(15,7)$ & $4(13,8)$ & $4(18,2)$ & \\
\hline
\end{tabular}

Có sự liên quan giữa giai đoạn bệnh với chỉ số SII $(p<0,05)$. Các đặc điếm còn lại không có sự khác biệt giữa hai nhóm SII cao và thấp.

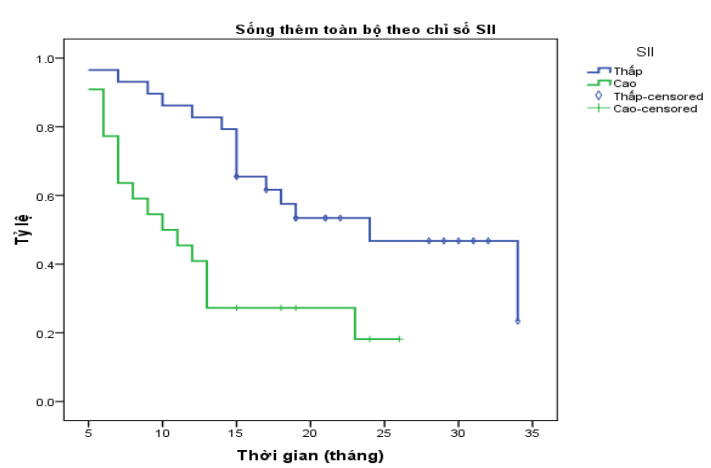

Biểu đồ 2. Sông thêm toàn bộ theo chỉ số SII trước điều trị

Nhóm có chỉ số SII cao ( $\geq 1.409)$ có thời gian sống thêm toàn bộ trung bình thấp hơn so với nhóm có chỉ số SII thấp (<1.409): 23,7 tháng so với 13,1 tháng, tỷ lệ sống thêm toàn bộ 1 năm, 2 năm là $40,9 \%$ và $18,2 \%$ so với $65,5 \%$ và $46,8 \%$. Sự khác biệt có ý nghĩa với $p=0,003$.

Bảng 3. Phân tích đơn biến các yếu tố tiên lượng ảnh hưởng đến sống thêm toàn bộ

\begin{tabular}{|c|c|c|c|}
\hline \multicolumn{2}{|c|}{ Các yếu tố tiên lượng } & \multirow{2}{*}{$\begin{array}{c}\text { Thời gian } \\
\text { sống thêm } \\
\text { trung bình } \\
\text { (tháng) } \\
18,9\end{array}$} & \multirow{2}{*}{$\mathbf{p}$} \\
\hline \multirow{2}{*}{ Giới } & Nam & & \\
\hline & Nữ & 19,8 & 0,609 \\
\hline \multirow{2}{*}{ Tuổi } & $<60$ & 20,7 & \multirow[b]{2}{*}{0,674} \\
\hline & $\geq 60$ & 18,8 & \\
\hline
\end{tabular}

\begin{tabular}{|c|c|c|c|}
\hline \multirow{2}{*}{ Chỉ số PS } & $0-1$ & 24,7 & \multirow[b]{2}{*}{0,000} \\
\hline & 2 & 14,0 & \\
\hline \multirow{2}{*}{$\begin{array}{c}\text { Giai đoạn } \\
\text { u }\end{array}$} & $\mathrm{T} 1,2$ & 20,3 & \multirow[b]{2}{*}{0,720} \\
\hline & $\mathrm{T} 3,4$ & 19,5 & \\
\hline \multirow{2}{*}{$\begin{array}{c}\text { Giai đoạn } \\
\text { hạch }\end{array}$} & $N(-)$ & 23,3 & \multirow[b]{2}{*}{0,461} \\
\hline & $\mathrm{N}(+)$ & 18,8 & \\
\hline $\begin{array}{l}\text { Giai } \\
\text { đoạn }\end{array}$ & III & 24,2 & 0,030 \\
\hline \multirow{2}{*}{$\begin{array}{c}\text { Mô bệnh } \\
\text { học }\end{array}$} & $\begin{array}{c}\text { Ung thư biếu mô } \\
\text { tuyến }\end{array}$ & 20,7 & \multirow[b]{2}{*}{0,122} \\
\hline & $\begin{array}{l}\text { Ung thư không } \\
\text { phải biểu môtuyyên }\end{array}$ & 13,1 & \\
\hline \multirow{2}{*}{$\begin{array}{c}\text { Chỉ số } \\
\text { SII }\end{array}$} & Thấp (<1.409) & 23,7 & \multirow[b]{2}{*}{0,003} \\
\hline & Cao $(\geq 1.409)$ & 13,1 & \\
\hline
\end{tabular}

Theo phân tích đơn biến, chỉ số PS, giai đoạn bệnh, chỉ số SII có giá trị tiên lượng với sống thêm thêm toàn bộ của nhóm nghiên cứu.

Bảng 4: Phân tích đa biên các yếu tô ảnh hưởng đến sống thêm toàn bộ

\begin{tabular}{|c|c|c|c|}
\hline \multicolumn{2}{|c|}{$\begin{array}{c}\text { Các yếu tố tiên } \\
\text { lượng }\end{array}$} & $\begin{array}{c}\text { HR } \\
(95 \% \mathrm{CI})\end{array}$ & \\
\hline $\begin{array}{c}\text { Chỉ số } \\
\text { PS }\end{array}$ & $\begin{array}{l}0-1 \\
2\end{array}$ & $\begin{array}{c}3,33(1,39- \\
7,96)\end{array}$ & 0,007 \\
\hline $\begin{array}{l}\text { Giai } \\
\text { đoạn }\end{array}$ & $\frac{\text { III }}{\text { IV }}$ & $\begin{array}{c}0,80(0,29- \\
2,23)\end{array}$ & 0,681 \\
\hline $\begin{array}{c}\text { Chỉ số } \\
\text { SII }\end{array}$ & $\begin{array}{c}\text { Thấp (< } \\
1.049) \\
\text { Cao }(\geq\end{array}$ & $\begin{array}{c}0,37(0,16- \\
0,82)\end{array}$ & 0,015 \\
\hline
\end{tabular}


Theo phân tích đa biến, chỉ số PS, chỉ số SII có giá trị tiên lượng độc lập với sống thêm toàn bộ của nhóm nghiên cứu.

\section{BÀN LUÂN}

Viêm, đặc biệt là viêm mãn tính đóng vai trò quan trọng trong sinh bệnh học của nhiều loại loại khối u trong đó có ung thư phổi. Viêm mãn tính liên quan tới quá trình ức chế đáp ứng miễn dịch chống $u$ và quá trình tạo mạch hàn gắn vết thương tạo điều kiên cho quá trình phát triển khối u. Cytokin là phức hợp quan trọng của quá trình viêm, sự biểu hiện của phức hợp này có thể dẫn đến thay đổi về mức độ lympho bào, bạch cầu đa nhân trung tính và tiểu cầu [2]. Lympho bào, bạch cầu đa nhân trung tính và tiểu câu có liên quan đến quá trình điều hòa sự phát triển khối u cả ở phương diên tích cực và tiêu cực. Tế bào lympho $T$ tuần hoàn với tính đặc trưng cho các kháng nguyên kháng $u$, trong khi đó các loại khác của lympho bào như tế bào $T$ điều hòa có thể ức chế loại lympho chống u khác như lympho gây độc tế bào. Bạch cầu đa nhân cũng có cả vai trò thúc đẩy và ức chế u. Bạch cầu đa nhân có thể ức chế đáp ứng miễn dịch chống u. Có nhiều bằng chứng cho thấy bạch cầu đa nhân trung tính bảo vệ tế bào u trong quá trình trình di căn. Bạch câu đa nhân trung tính tạo bước trung gian cho quá trình xâm nhập và di căn, ức chế tế bào giết tư nhiên (NK) và thúc đầy quá trình xâm nhập mạch của tế bào $u$, phần lớn nhờ việc tiết ra enzym thủy phân protein cấu trúc (MMPmatrix metalloproteinase) [5].

Tiểu cầu tạo điêu kiện cho cho việc di chuyển của tế bào u và có thể có vai trò đưa tế bào u di căn đến các cơ quan khác. Tiểu cầu tác động đến tế bào $u$ dẫn đến việc gắn với tế bào $u$, dẫn dắt tế bào $u$ xuyên qua lớp biểu mô và phức hợp bảo vệ miễn dịch. Tiểu câu còn có vai trò giúp lan tràn tế bào u qua việc làm mạnh lên các quá trình bao gồm cả quá trình tương tác giữa các phân tử liên kết tế bào như selectin và integrin với tế bào u [2].

Đã có nhiêuu nghiên cứu chứng minh giá trị tiên lượng của một số marker về viêm với đáp ứng điều trị cũng như sống thêm của UTPKTBN. Trong đó có các chỉ số như tỷ lệ bạch cầu đa nhân trung tính/lympho bào, số lượng tiểu cầu hay tỷ lệ tiểu câu/lympho bào. Dựa trên những nghiên cứu này, chỉ số SII (tiểu cầu $x$ tỷ lệ bạch cầu đa nhân trung tính/lympho bào) đã được một số nghiên cứu khẳng định có giá trị tiển lượng với đáp ứng điều trị cũng như sống thêm của bệnh nhân UTPKTBN[1],[3],[6],[7].
Tong và cộng sự (2017), nghiên cứu giá trị tiên lượng của các yếu tố SII, tỷ lệ bạch cầu đa nhân/lympho bào (NLR), tỷ lệ tiểu cầu/lympho bào (PLR), chỉ số dinh dưỡng (PNI) trên 332 bệnh nhân UTPKTBN giai đoạn III. Áp dụng điểm cut-off của chỉ số SII $\geq 660$, NLR $\geq 3,57$; $\mathrm{PLR} \geq 147 ; \mathrm{PNI} \leq 52,95$. Kết quả, chỉ số $\mathrm{SII} \geq 660$ có tương quan với ECOG PS cao $(p<0,001)$, giai đoạn khối u muộn $(p<0,001)$, giai đoạn bệnh tiên triển $(p=0,019)$, và tỷ lệ đáp ứng thấp $(p=0,018)$. Các bệnh nhân có SII 2660 có thời gian sống thêm toàn bộ trung bình là 10 tháng, các bệnh nhân có SII <660 có thời gian sống thêm toàn bộ trung bình là 30 tháng. Phân tích đa biến cho thấy SII có giá trị tiên lượng độc lập với thời gian sống thêm của bệnh nhẩn UTPKTBN [6].

Guo (2018) đánh giá vai trò của chỉ số SII trước điều trị trên 142 bệnh nhân UTPKTBN giai đoạn III, IV. Kết quả: SII cao tỷ lệ thuận với thời gian sống thêm không tiến triển và tỷ lệ sống thêm toàn bộ (với nhóm SII thấp, thời gian sống thêm không bệnh và sống thêm toàn bộ là 13 tháng và 16,5 tháng so với 8 tháng và 13,5 tháng ở nhóm SII cao, $p<0,001$ [3].

Berardi (2019) nghiên cứu trên 311 bệnh nhân UTPKTBN giai đoạn lan tràn điều trị hóa trị bước một hoặc điều trị đích. Bệnh nhẩn được chia thành 2 nhóm, nhóm $A$ có SII $\geq 1.270$ và nhóm $B$ có $S I I<1.270$. Kết quả: nhóm $A$ có thời gian sống thêm toàn bộ là 12,4 tháng; nhóm $B$ có thời gian sống thêm toàn bộ là 21,7 tháng $(p<0,001)$, thời gian sống thêm không tiến triển lần lượt là 3,3 và 5,2 tháng $(p=0,029)$. Tác giả kết luận chỉ số SII có giá trị tiên lượng đặc hiệu với bệnh nhân UTPKTBN điều trị bước một [1].

Nghiên cứucủa chúng tôi thực hiện trên 51 bệnh nhân UPTKTBN giai đoạn III, IV, điêuu trị hóa chất bước một (đều là các phác đồ có platinum). Chúng tôi đưa ra những đặc điểm chung của đối tượng nghiên cứu, dựa trên đó khảo sát mối liên quan giữa các đặc điểm cơ bản này với kết quả sống thêm của nhóm nghiên cứu. Các yếu tố cơ bản như giới, nhóm tuổi, chỉ số PS, giai đoạn, phân loại mô bệnh học, chỉ số CEA trước điêu trị, phác đồ điều trị và chỉ số SII.

Về chỉ số SII, sử dụng đường cong ROC chúng tôi đã xác định được chỉ số này có giá trị tiên lượng với sống thêm toàn bộ của nhóm bệnh nhân nghiên cứu. Điểm cut-off tối ưu của chỉ số SII là 1.409. Dựa trên điểm cut-off này chúng tôi chia hai nhóm bệnh nhân theo mức độ cao hay thấp của chỉ số SII (<1.409 và $\geq 1.409)$. Chúng tôi thấy có mối liên quan giữa giai đoạn 
và mức độ cao thấp của chỉ số SII. Phân tích đơn biến xác định được các yếu tố ảnh hưởng tới thời gian sống thêm của nhóm bệnh nhân nghiên cứu là chỉ số PS, giai đoạn bệnh và chỉ số SII. Thời gian sống thêm trung bình của bệnh nhân trong nghiên cứu của chúng tôi là là 23,7 tháng ở nhóm SII thấp và 13,1 tháng ở nhóm có SII cao; tỷ lệ sống thêm toàn bộ 1 năm, 2 năm là 40,9\% và $18,2 \%$ so với $65,5 \%$ và $46,8 \%(p=0,003)$. Qua phân tích đa biến cho thấy chỉ số SII trước điều trị, chỉ số PS là yếu tố tiên lượng độc lập cho sống thêm toàn bộ. Các kết quả này cũng tương tự như kết quả nghiên cứu của các tác giả đã nêu trên, đã góp phần khẳng định giá trị tiên lượng của chỉ số SII trong UTPKTBBN giai đoạn tiến triển, di căn.

Tuy nhiên nghiên cứu của chúng tôi còn có một số hạn chế đó là số lượng bệnh nhân chưa nhiều; mắc dù phương pháp điêu trị đều là các phác đồ hóa chất có platinum, nhưng kết hợp không đồng nhất với nhiều loại hóa chất khác nhau. Bên cạnh đó đây là một nghiên cứu hồi cứu nên còn có một số chỉ số chưa khảo sát được do chưa được chỉ định đầy đủ hoặc chưa được triển khai thường quy tại trung tâm như chỉ số CEA (chỉ ghi nhận được trên 29/51 bệnh nhân), tình trạng đột biến gen EGFR, hay một số marker về viêm khác. Các yếu tố chưa được khảo sát trên rất có thể là những yếu tố có giá trị tiên lượng liên quan tới kết quả điều trị của bệnh nhân.

\section{KẾT LUẬN}

Chỉ số viêm miễn dịch hệ thống SII là một marker có giá trị tiên lượng độc lập cho sônng thêm của bệnh nhân ung thư phổi không tế bào nhỏ giai đoạn tiến triển, di căn hóa trị bước một. Chúng tôi đề xuất tiếp tục nghiên cứu trên số lượng bệnh nhân lớn hơn kết hợp phân tích một sốmarker khác, đặc biệt là các marker về viêmđể có thể khẳng định được đầy đủ giá trị tiên lượng của chỉ số này trong ung thư phổi không tế bào nhỏ.

\section{TÀI LIÊU THAM KHẢO}

1. Berardi, R., Santoni, M., Rinaldi, S., et al., "Pre-treatment systemic immune-inflammation represents a prognostic factor in patients with advanced non-small cell lung cancer", Ann Transl Med, 2019, 7(20), p. 572.

2. Cannon, N. A., Meyer, J., Iyengar, P., et al., "Neutrophil-lymphocyte and platelet-lymphocyte ratios as prognostic factors after stereotactic radiation therapy for early-stage non-small-cell lung cancer", ] Thorac Oncol, 2015, 10(2), pp. 280-5.

3. Guo, D., Zhang, J., Jing, W., et al., "Prognostic value of systemic immune-inflammation index in patients with advanced non-small-cell lung cancer", Future Oncol, 2018, 14(25), pp. 2643-2650.

4. NSCLC Meta-analysis Collaborative Group, "Preoperative chemotherapy for non-small-cell lung cancer: a systematic review and meta-analysis of individual participant data", Lancet, 2014,. 383(9928), pp. 1561-71.

5. Schernberg, A., Mezquita, L., Boros, A., et al., "Neutrophilia as prognostic biomarker in locally advanced stage III lung cancer", PLoS One, 2018, 13(10), p. e0204490.

6. Tong, Y. S., Tan, J., Zhou, X. L., et al.(2017), "Systemic immune-inflammation index predicting chemoradiation resistance and poor outcome in patients with stage III non-small cell lung cancer", J Transl Med, 2017, 15(1), p. 221.

7. Wang, Y., Li, Y., Chen, P., et al.(2019), "Prognostic value of the pretreatment systemic immune-inflammation index (SII) in patients with non-small cell lung cancer: a meta-analysis", Ann Transl Med, 2019, 7(18), p. 433.

\section{ĐÁNH GIÁ KẾT QUẢ ĐÎ̀̂U TRI SỎI ĐƯờNG MÂT TRONG GAN BẰNG PHẪU THUÂT NộI SOI VÀ SỬ DỰG ỐNG SOI MỀM TÁN THỦY LỰC QUA ỐNG NỔI MẬT DA TẠI BỆNH VIỆN TRUNG ƯO'NG QUÂN ĐộI 108}

\section{TÓM TẮT}

\footnotetext{
${ }^{1}$ Trường Đại học Y Dược, Đại học Thái Nguyên ²Bênh viện 108

Chịu trách nhiệm chính: Vũ Việt Đức

Email: vuvietducdty@gmail.com

Ngày nhận bài: 15.10.2020

Ngày phản biện khoa học: 20.11.2020

Ngày duyệt bài: 7.12.2020
}

\section{Vũ Việt Đức ${ }^{1}$, Lê Văn Thành², Trần Đức Quý1}

Mục tiêu: đánh giá kết quả điều trị sỏi đường mật trong gan bằng phẫu thuật nôi soi và sử dụng ống soi mềm tán thủy lực qua ống nối mật - da. Đối tượng: Gồm 60 bệnh nhân được chẩn đoán xác định sơi đường mật trong gan băng siêu âm hoặc cộng hưởng từ được tiến hành phẫu thuât nội soi và sử ống soi mềm tán thủy lực qua ống nối mật da tại bệnh viện Trung ương Quân đội 108 tự 01/01/2018 đến 30/06/2020. Phương pháp nghiên cứu: Nghiên cứu mô tả, hồi cứu. Kết quả: 60 bênh nhân sỏi đường mật trong gan có hoặc không kết hợp với sỏi đường 